\title{
Livre Saber (LiSa): Um Repositório de Recursos Educacionais Abertos de Cursos a Distância
}

\author{
Livre Saber(LiSa): an open educational resource repository of distance education \\ courses
}

Joice Lee Otsuka

Departamento de Computação Universidade Federal de São Carlos

joice@dc.ufscar.br

Gislaine Cristina Micheloti Rosales Instituto Federal de Educação, Ciência e Tecnologia de São Paulo - Campus

Araraquara

gimicheloti@gmail.com

\author{
Elis Gabriela Copa dos Santos \\ Bach em Ciência da Informação \\ Universidade Federal de São Carlos \\ elisgabriela@gmail.com
}

\section{Cristian Kawakami}

Secretaria de Educação a Distância Universidade Federal de São Carlos chrys@sead.ufscar.br

\author{
Luciana de Souza Gracioso \\ Depto de Ciência da Informação \\ Universidade Federal de São Carlos \\ luciana@ufscar.br
}

\begin{abstract}
Resumo Este artigo apresenta o Livre Saber (LiSa), um repositório digital de recursos educacionais abertos criado com o intuito de organizar, preservar e compartilhar um acervo de materiais didáticos em diferentes formatos (vídeos, animações, jogos, podcasts, ilustrações, textos etc.) que vem sendo criado no escopo dos cursos oferecidos na modalidade EaD pela Universidade Federal de São Carlos. São apresentadas considerações técnicas sobre a política de acesso e arquivamento do LiSa; a sua estrutura e conjunto de metadados e o fluxo de depósito. Também são analisados alguns resultados iniciais da implantação.
\end{abstract}

Palavras-Chave: Repositórios digitais; Educação a Distância; Recursos Educacionais Abertos.

\begin{abstract}
This paper presents Livre Saber (LiSa), a digital repository of open educational resources created aiming to organize, to preserve and to share a collection of teaching materials in different formats (videos, animations, games, podcasts, illustration and texts) that has been created within the scope of courses offered in distance education modality at Federal University of São Carlos. Technical issues regarding LiSa are presented: its access and publishing policy; its structure and set of metadata; its publishing flow. Some initial results of LiSa implementation are also presented.
\end{abstract}

Keywords: Digital repositories; Distance education; Open Educational Resources. 


\section{Introdução}

$\mathrm{O}$ acesso livre a recursos educacionais é um requisito essencial para a educação democrática, de qualidade, sustentável e aberta, em qualquer modalidade (presencial, a distância, híbrida) e em todos os níveis de formação. Além do acesso, o reuso desses recursos deve ser promovido, considerando o alto custo de sua produção que, em geral, envolve um trabalho conjunto entre especialistas do conteúdo e uma equipe multidisciplinar, sobretudo quando consideramos os recursos educacionais interativos e que integram diferentes mídias e tecnologias.

Neste sentido, o desenvolvimento e o compartilhamento dos denominados Recursos Educacionais Abertos (REA) - que são recursos com licença aberta que podem ser consultados, revisados e reutilizados - deve ser amplamente promovido e apoiado. No entanto, esta prática é ainda pouco difundida, principalmente no contexto nacional. Algumas iniciativas de apoio ao desenvolvimento de conteúdos educacionais foram e vêm sendo promovidas por órgãos públicos, tais como o projeto RIVED (Rede Interativa Virtual de Educação) ${ }^{1}$ e chamadas públicas como a aberta em 2007 pelo MCT/FINEP/MC/FUNTTEL para o desenvolvimento de conteúdos digitais ${ }^{2}$, mas pouco tem se investido na divulgação e indução do desenvolvimento e uso de REA, como um modelo mais democrático e sustentável de desenvolvimento e acesso aos conteúdos educacionais.

No escopo da Educação a Distância (EaD), o sistema Universidade Aberta do Brasil (UAB) tem promovido a produção de recursos educacionais em diferentes mídias para apoiar cursos oferecidos na modalidade EaD. No entanto, um estudo de Pinto, Ribeiro \& Serra [1] mostra que, no âmbito do sistema UAB, poucas ações têm sido promovidas para que esses recursos sejam produzidos e compartilhados como recursos educacionais abertos, favorecendo o reuso e a produção colaborativa. Esse estudo foi realizado com 96 instituições integrantes do Sistema UAB, buscando identificar práticas de utilização ou produção de REA e mostra que apenas $23 \%$ dessas instituições utilizam ou produzem REA, mas $100 \%$ das instituições pretendem continuar ou passar a utilizar e produzir REA para seus cursos. Neste mesmo estudo são apontadas algumas causas para o baixo índice de uso/produção de REA: (i) o desconhecimento sobre o assunto; (ii) a falta de domínio das tecnologias; e (iii) questões de direitos autorais.

O presente artigo tem como objetivo compartilhar a experiência da Secretaria Geral de Educação a Distância (SEaD) da Universidade Federal de São Carlos (UFSCar)

\footnotetext{
${ }^{1}$ http://rived.mec.gov.br/

${ }^{2} \mathrm{http}: / /$ www.finep.gov.br/editais/encerrados.asp
}

na implantação do repositório digital Livre Saber $(\mathrm{LiSa})^{3}$, no qual estão sendo organizados e disponibilizados recursos educacionais que vem sendo produzidos para os cursos de graduação e especialização oferecidos na modalidade a distância pela UFSCar. Todos os recursos estão sendo catalogados e disponibilizados no LiSa como REA, sob a licença Creative Commons ${ }^{4}$ (CC), com o intuito de favorecer a adaptação, reuso, remixagem e redistribuição.

As próximas seções estão organizadas da seguinte forma: a seção 2 apresenta algumas definições e considerações relacionadas aos Recursos Educacionais Abertos, bem como a importância destes no movimento da Educação Aberta; a seção 3 apresenta alguns conceitos relacionados aos repositórios digitais; a seção 4 apresenta detalhes sobre a implantação e gestão do repositório digital Livre Saber (LiSa) e na seção 5 é apresentada uma análise dos resultados iniciais da implantação. Na seção 6 estão algumas considerações finais sobre este trabalho.

\section{Recursos Educacionais Abertos}

O termo Recursos Educacionais Abertos (REA) foi cunhado em 2002 pela United Nations Educational Scientific and Cultural Organization (UNESCO) como [2]:

\footnotetext{
A disponibilização de recursos educacionais, por meio de tecnologias de informação e comunicação, para consulta, uso e adaptação, por uma comunidade de usuários sem fins comerciais. (p. 30, tradução nossa).
}

Esta definição original é bastante ampla e destaca a abertura do conteúdo para consulta, uso e adaptação sem fins comerciais.

Neil Butcher, na obra "A Basic Guide to Open Educational Resources" [3] preparada em 2011 para a Commonwealth of Learning \& UNESCO, define REA como:

qualquer recurso educacional (incluindo mapas curriculares, materiais de cursos, livros texto, vídeos, aplicações multimídia, podcasts e qualquer outro material projetado para o ensino $\mathrm{e}$ aprendizagem) que estão abertos para educadores e estudantes, sem a necessidade de pagamento de direitos autorais ou taxas de licença. (p. 5, tradução nossa).

Segundo esta definição, são características principais dos REA terem cunho educacional e serem abertos. A distribuição como conteúdo aberto é característica

${ }^{3} \mathrm{http}: / /$ livresaber.sead.ufscar.br/

${ }^{4} \mathrm{http} / / /$ creativecommons.org/ 
essencial para viabilizar um reuso efetivo desses recursos, considerando que frequentemente são necessárias revisões, atualizações e adaptações desses recursos para que possam ser utilizados em novos contextos.

Um dos marcos iniciais do movimento REA foi a fundação do projeto Creative Commons em 2001 [2], que possibilitou a criação de um conjunto de licenças flexíveis (os autores podem licenciar suas obras permitindo ou não a adaptação, remixagem e redistribuição com uso comercial).

Butcher [3] destaca que o compartilhamento público sob licença aberta é uma forma segura de proteger os direitos de propriedade intelectual do autor, já que o seu conteúdo sempre será atribuído ao seu autor original. Além disso, o fácil acesso à obra original facilita a identificação de plágio ou uso indevido.

Wiley [4] descreve quatro formas de uso de um conteúdo aberto, sem custo e sem necessidade de solicitação de permissão de uso, conhecido como 4Rs:

1. Reusar - fazer e usar cópias literais do trabalho, em sua forma original

2. Revisar - alterar ou transformar o trabalho, de forma que ele atenda melhor às suas necessidades

3. Remixar - combinar o trabalho (original ou alterado) com outros conteúdos que atendam melhor às suas necessidades

4. Redistribuir - compartilhar o trabalho original ou revisado ou remixado com outras pessoas. (p.9, tradução nossa).

Em 2007, a Open Society Foundations (OSF) e a Shuttleworth Foundation convocaram uma reunião na Cidade do Cabo, da qual resultou a "Declaração de Cidade do Cabo para Educação Aberta", uma carta de princípios, estratégias e compromissos voltados à estimular o diálogo e a ação que levem ao crescimento da Educação Aberta. Foram propostas três estratégias para aumentar o alcance e o impacto de Recursos Educacionais Abertos [5]:

1. Educadores e estudantes: Primeiramente, nós encorajamos educadores e estudantes a participarem ativamente neste movimento emergente de educação aberta. Esta participação inclui: a criação, utilização, adaptação e melhoria dos recursos educacionais abertos; abraçando práticas educativas construídas em torno da colaboração, da descoberta e da criação de conhecimento; e convidando seus pares e colegas a participarem. A criação e uso de recursos educacionais abertos devem ser considerados partes integrantes da educação e devem ser apoiados e recompensados adequadamente.
2. Recursos Educacionais Abertos: Em segundo lugar, apelamos aos educadores, autores, editores e instituições para libertar os seus recursos abertamente. Estes recursos educacionais abertos devem ser livremente compartilhados por meio de licenças livres que facilitam o uso, revisão, tradução, melhoria e compartilhamento por qualquer um. Os recursos devem ser publicados em formatos que facilitem tanto a utilização e edição, e adaptáveis a diferentes plataformas tecnológicas. Sempre que possível, eles também devem estar disponíveis em formatos que sejam acessíveis às pessoas com deficiências e a pessoas que não tenham ainda acesso à Internet.

3. Política Pública de Educação Aberta: Em terceiro lugar, governos, conselhos escolares, faculdades e universidades devem fazer da Educação Aberta uma alta prioridade. Idealmente, recursos educacionais financiados com recursos públicos devem ser abertos. Processo de certificação e de adoção devem dar preferência a recursos educacionais abertos. Repositórios de recursos educacionais devem incluir ativamente e destacar recursos educacionais abertos dentro de suas coleções. (p.1-2, tradução nossa).

Além do acesso aberto, outra questão essencial para promover a preservação e recuperação dos recursos educacionais abertos é a catalogação e a organização desses recursos em Repositórios Digitais Abertos. A seção seguinte apresenta as principais características desses repositórios.

\section{Repositórios Digitais}

Repositórios digitais são ambientes virtuais destinados a receber objetos digitais. Nestes ambientes, tais objetos podem ser armazenados, acessados e recuperados, por meio de mecanismos de importação, exportação, armazenamento e recuperação de conteúdos [6]. Repositórios diferem de bibliotecas ou outros acervos digitais, pois armazenam a produção contemporânea e própria da instituição, ou seja, o armazenam o conhecimento ao mesmo tempo em que ele está sendo produzido, enquanto bibliotecas armazenam um conhecimento produzido externamente e sem qualquer relação institucional.

Tradicionalmente, as bibliotecas têm gerido as informações produzidas por organizações, ou seja editores, externas às instituições às quais são ligadas. Elas selecionam, adquirem, organizam, tornam acessível, promovem, preservam e instruem as pessoas sobre como usar esses recursos de informação. No entanto, os desenvolvedores de repositórios digitais estão 
principalmente preocupados com o conteúdo gerado internamente, ou seja, com a produção intelectual (geralmente em formato digital) de suas comunidades universitárias [7].

Além disso, também podem ser apontadas algumas características operacionais para tal distinção. Segundo Herry e Anderson [8], um repositório digital se diferencia de outras coleções digitais pelas seguintes características:

- o conteúdo é depositado em um repositório pelo criador, proprietário ou por terceiro;

- a arquitetura do repositório gerencia tanto conteúdo quanto metadados;

- o repositório oferece um conjunto mínimo de serviços básicos, tais como inserção, recuperação, busca e controle de acesso;

- o repositório deve ser sustentável e confiável, bem apoiado e bem gerido. (p.2, tradução nossa)

É válido ressaltar que repositórios digitais são ferramentas de armazenamento e disseminação da informação que já existiam antes de movimentações em prol do acesso aberto, contudo ganharam força e espaço, cada vez maior, ao serem apresentados como estratégias para se alcançar o acesso aberto. Assim, os mesmos autores (op. cit.) ainda definem as características pelas quais repositórios de livre acesso distinguem-se dos demais:

- devem prover acesso aberto para os seus conteúdos (salvas as restrições legais)

- devem prover acesso aberto aos seus metadados para coleta por outros sistemas (harvesting). (p.2, tradução nossa)

Dessa forma, os conteúdos digitais armazenados em repositórios digitais são descritos por meio de um conjunto de metadados (informações sobre o conteúdo), geralmente seguindo um padrão, como o Dublin Core $^{5}$ e o Learning Object Metadata (LOM) ${ }^{6}$. A adoção de um padrão de metadados é fundamental para garantir a interoperabilidade com outros repositórios e sistemas. Os metadados são utilizados para facilitar a busca, a avaliação, a recuperação e o uso desses objetos de aprendizagem [9]. A organização por meio de metadados é especialmente importante quando trabalhamos com recursos multimídia que, ao contrário dos recursos textuais, não são facilmente indexados a partir de seu próprio conteúdo.

Diante desses pressupostos, a Secretaria Geral de Educação a Distância (SEaD) da UFSCar implantou, em 2011, o repositório digital Livre Saber (LiSa), com o intuito de organizar, preservar e favorecer o acesso aos REA desenvolvidos no escopo dos cursos oferecidos na

\footnotetext{
${ }^{5} \mathrm{http}: / /$ dublincore.org/

${ }^{66} \mathrm{http} / / /$ standards.ieee.org/findstds/standard/1484.12.1-2002.html
}

modalidade EaD na UFSCar. A seção a seguir é destinada a apresentá-lo.

\section{Livre Saber (LiSa)}

Desde 2007, a Universidade Federal de São Carlos (UFSCar) vem desenvolvendo iniciativas de Educação a Distância, grande parte no escopo do Sistema UAB, por meio do qual atualmente são oferecidos cinco cursos de graduação (Licenciatura em Pedagogia, Licenciatura em Educação Musical, Tecnologia Sucroalcooleira, Bacharelado em Engenharia Ambiental e Bacharelado em Sistemas de Informação) e dois cursos de especialização (Educação para as Relações Étnico-Raciais e Gênero e Diversidade na Escola).

Os cursos da modalidade EaD na UFSCar são desenvolvidos em um ambiente virtual de aprendizagem (AVA), tendo como plataforma o software livre Moodle ${ }^{7}$. No AVA são desenvolvidas diversas atividades de aprendizagem ao longo das disciplinas, com o intuito de promover processos de ensino e aprendizagem alinhados com os objetivos propostos. Para apoiar esses processos são desenvolvidos materiais educacionais em diferentes mídias: textos, ilustrações, áudios, vídeos, animações e jogos distribuídos por meio de diferentes tecnologias: web, digital (CD, DVD), impressa e móvel (tablet, celular e mp3/mp4 player). As diferentes mídias e tecnologias são utilizadas de forma complementar, procurando prover materiais educacionais que favoreçam os diferentes estilos de aprendizagem e o acesso por meio de diferentes tecnologias.

Com isso, todas as disciplinas que compõem os cursos da modalidade $\mathrm{EaD}$ da UFSCar devem contemplar: (i) o ambiente virtual de aprendizagem da disciplina (por meio da plataforma Moodle); (ii) material impresso (livro da disciplina); (iii) material audiovisual (vídeos de introdução à disciplina, videoaulas, animações e podcasts) e (iv) webconferências.

Outra grande preocupação da $\mathrm{SEaD}$, tanto durante a criação quanto na disponibilização dos recursos educacionais, é relativa às questões de acessibilidade. Assim, parte dos materiais produzidos recebe alguma forma de tratamento voltado a possibilitar sua utilização por pessoas com deficiência visual. Dessa forma, algumas animações estão sendo feitas utilizando a tecnologia HTML5, para facilitar a navegação por meio de teclado e a leitura por meio de softwares leitores de tela. As ilustrações, bem como trechos de animações e vídeos que possuem elementos visuais, recebem audiodescrição. Além disso, alguns vídeos já possuem uma janela com tradução para a Língua Brasileira de Sinais (LIBRAS).

\footnotetext{
${ }^{7}$ https://moodle.org/
} 
Nesse cenário, um amplo e rico acervo de materiais educacionais em diferentes mídias vem sendo criado para as disciplinas dos cursos oferecidos na modalidade a distância. Para favorecer o acesso e reuso desses recursos, SEaD da UFSCar vem trabalhando na catalogação e publicação desses materiais como recursos educacionais abertos. Para tanto, em 2011 foi implantado o Livre Saber (LiSa), um repositório digital de acesso livre da SEaD-UFSCar (Figura 1), onde materiais produzidos para os cursos da modalidade EaD da UFSCar, além de conteúdos produzidos no Laboratório de Objetos de Aprendizagem (LOA) ${ }^{8}$ da SEaD, estão sendo organizados e disponibilizados para acesso público, sob a licença Creative Commons.

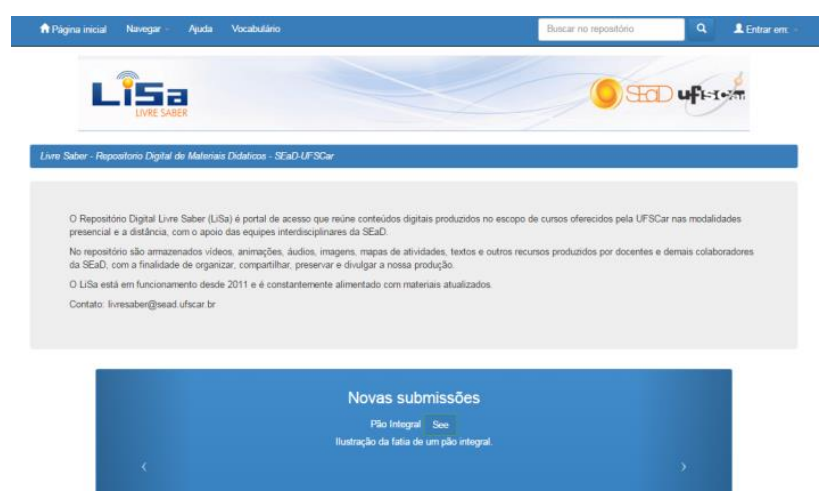

Figura 1 -Página inicial do LiSa

A implantação do LiSa, foi feita utilizando o sistema de gerenciamento de repositórios digitais DSpace ${ }^{9}$, é um software livre, podendo ser customizado de acordo com as necessidades da instituição. O DSpace, assim como grande parte das soluções de repositórios de código aberto executa o protocolo Open Archives Initiative Protocol for Metadata Harvesting (OAI-PMH) [10], que melhora a visibilidade dos conteúdos armazenados e permite a interoperabilidade entre repositórios, por meio da coleta dos metadados.

O Livre Saber participa do Serviço Experimental FEB (Federação Educa Brasil) ${ }^{10}$ da Rede Nacional de Ensino e Pesquisa (RNP), o qual tem o como propósito oferecer um serviço de federação, por meio do qual é possível a busca e acesso a diversos repositórios em um único portal. A adoção de um sistema de repositório digital que responde ao protocolo OAI-PMH foi essencial para possibilitar a participação do Livre Saber nessa iniciativa de federação.

\footnotetext{
${ }^{8}$ http://www.loa.sead.ufscar.br

${ }^{9} \mathrm{http}: / /$ www.dspace.org/

${ }^{10} \mathrm{http}: / /$ feb.ufrgs.br/
}

A implantação do LiSa partiu da catalogação dos materiais produzidos para os cursos de graduação da modalidade EaD da UFSCar entre 2007 e 2011, por serem materiais já revisados e validados pelos professores, estudantes e equipes. A quantidade e a diversidade de tipos de materiais a serem catalogados foram alguns dos desafios da implantação do repositório, como será apresentado nas subseções a seguir.

\subsection{Política de acesso e de publicação}

Todo conteúdo publicado no LiSa é de livre acesso, portanto acessá-lo basta apenas um computador com acesso à internet, sem a necessidade de realização de qualquer tipo de login. Somente para a gestão do repositório (catalogação, submissão, gerenciamento de usuários) é necessário acessar uma área de administração, por meio do login com senha. Sendo assim, a submissão dos materiais ao repositório é de total responsabilidade da equipe gestora.

A publicação dos materiais no LiSa é feita mediante a autorização dos autores do conteúdo e outros possíveis participantes do processo de criação do material. Os autores e integrantes das equipes de criação assinam termos de cessão dos direitos de autoria e de imagem que permitem que os conteúdos sejam disponibilizados publicamente no repositório digital Livre Saber, sob licença Creative Commons.

\subsection{Estrutura}

A navegação no DSpace é organizada em uma hierarquia composta por Comunidades, Subcomunidades e Coleções, sendo que os itens de conteúdo são publicados apenas nas Coleções. Com o intuito de facilitar a recuperação dos objetos publicados por curso, o Livre Saber foi organizado, inicialmente, em Comunidades representando cada categoria de curso (Graduação, Formação, Especialização) e em Subcomunidades, representando cada curso. Dentro de cada Subcomunidade, foram definidas Coleções para cada tipo de conteúdo, com o intuito de facilitar a identificação e recuperação de objetos por tipo (áudios, vídeos, animações, guias, livros etc.).

Com o crescimento das necessidades de armazenamento, novas categorias foram criadas entre 2011 e 2014 e, hoje, o Livre Saber está organizado da seguinte maneira: o primeiro menu de comunidades-topo apresenta seis categorias: (i) Aplicativos, jogos e softwares; (ii) Formação continuada a distância; (iii) Graduação a distância; (iv) Ilustrações Gerais; (v) Institucional e (vi) Tutoriais. 
Em “Aplicativos, jogos e softwares" estão sendo organizados jogos, aplicativos e softwares desenvolvidos em projetos do LOA e da SEaD/UFSCar, bem como os componentes desses recursos, tais como ilustrações (botões e ícones, personagens, cenários e telas), trilhas sonoras e efeitos sonoros.

Na comunidade "Formação continuada a distância" estão concentrados materiais voltados para o letramento do aluno de um curso a distância e materiais dos cursos de aperfeiçoamento apoiados pela $\mathrm{SEaD}$.
$\mathrm{Na}$ comunidade "Graduação a distância" estão os materiais produzidos para os cinco cursos de graduação oferecidos pela SEaD, já mencionados. Desta forma, a comunidade topo está dividida em subcomunidades, representadas pelos cursos. E cada subcomunidade organiza os materiais em coleções de acordo com o formato do material. Ao todo são dez coleções distribuídas pelas subcomunidades, cuja organização é descrita na Tabela 1.

\begin{tabular}{|c|c|c|c|c|}
\hline $\begin{array}{c}\text { Engenharia } \\
\text { Ambiental }\end{array}$ & $\begin{array}{c}\text { Licenciatura em } \\
\text { Educação Musical }\end{array}$ & $\begin{array}{c}\text { Licenciatura em } \\
\text { Pedagogia }\end{array}$ & $\begin{array}{c}\text { Sistemas de } \\
\text { Informação }\end{array}$ & $\begin{array}{c}\text { Tecnologia } \\
\text { Sucroalcooleira }\end{array}$ \\
\hline Animações & Alustrações & Ilustrações & Animações & Ilustrações \\
\hline Ilustrações & $\begin{array}{c}\text { Textos e } \\
\text { apresentações }\end{array}$ & $\begin{array}{c}\text { Textos e } \\
\text { apresentações }\end{array}$ & $\begin{array}{c}\text { Textos e } \\
\text { apresentações }\end{array}$ \\
\hline $\begin{array}{c}\text { Textos e } \\
\text { apresentações }\end{array}$ & Livros Falados & & & Podcasts \\
\hline & Maximinivídeos & & Podcasts & Vídeos \\
\hline Podcasts & Vídeos & Vídeos & Vídeos & \\
\hline Vídeos & Vinhetas & & & \\
\hline & &
\end{tabular}

Tabela 1 - Subcomunidade e coleções da comunidade “Graduação a Distância”. (Autoria própria)

A comunidade "Ilustrações Gerais" recebe os demais trabalhos gráficos desenvolvidos pela equipe audiovisual, como figuras utilizadas em vídeos e animações, que não se enquadram no contexto de disciplinas ou cursos específicos ou outros materiais ilustrativos criados para fins institucionais da $\mathrm{SEaD}$, como ilustrações de sites e animações.

A comunidade "Institucional" foi criada com a finalidade de receber documentos, planilhas, formulários, termos e demais possíveis conteúdos administrativos da $\mathrm{SEaD}$.

E em "Tutoriais" estão diversos tutoriais produzidos pela $\mathrm{SEaD}$, agrupados nas coleções de acordo com o programa a que se destinam.

\subsection{Metadados e catalogação}

O conjunto teórico mínimo que norteou os pontos de partida prévios para o tratamento descritivo e temático dos conteúdos no LiSa foram: as normas ABNT 6023 de Informação e documentação Referências Elaboração [11], o AACR2 (Anglo American Cataloging Rules ${ }^{11}$ e as orientações gerais do padrão de metadados Dublin Core para a representação temática dos conteúdos, isto é, a delimitação de seus assuntos principais, utilizamos metodologias de análise

\footnotetext{
${ }^{11}$ http://www.aacr2.org/
}

documentária para a construção de resumos descritivos e levantamento de palavras-chave.

Assim, neste contexto será chamado de catalogação todo o processo de tratamento descritivo e temático dos materiais submetidos ao repositório. No âmbito das áreas que se ocupam destas atividades (a Biblioteconomia, a Documentação, a Ciência da Informação, dentre outras), a representação descritiva se incumbe dos processos envolvidos com a padronização dos dados descritivos referentes ao objeto a ser catalogado e à representação temática, dos aspectos relacionados à delimitação de assuntos destes conteúdos e à padronização no uso da linguagem para descrevê-los.

A descrição do conteúdo armazenado em um documento requer uma espécie de tradução, por meio de elementos que sejam capazes de fornecer informações sobre o conteúdo, o suporte e a sua localização. Estes são os metadados, que além de simples descritores, provêm informações a respeito de diversas dimensões do documento, possibilitando a identificação, o compartilhamento, a utilização/reutilização, o gerenciamento, a recuperação, a interoperabilidade e o relacionamento entre o recurso descrito e os demais recursos presentes na coleção. Por isso o preenchimento destes elementos é tão importante no processo de depósito dos materiais no repositório. Padrões de metadados permitem a interoperabilidade entre os diversos sistemas de armazenamento e descoberta. Esses padrões são conjuntos de metadados previamente criados 
e amplamente utilizados que permitem que os mecanismos de busca reconheçam as informações estruturadas providas pelos metadados atribuídos aos recursos descritos.

Hoje existem diversos padrões e outros vêm sendo desenvolvidos. Conforme mencionado anteriormente, o padrão adotado no LiSa é o Dublin Core (DC), por ser o conjunto de metadados disponível no DSpace e por contemplar um conjunto essencial para a descrição dos recursos educacionais. É um conjunto abrangente, sendo adequado aos diversos contextos, pois permite que seus campos sejam utilizados de acordo com o nível de detalhamento que se pretende atingir na descrição do recurso e é adaptável, sendo frequentemente reduzido ou expandido de acordo com as necessidades locais.

O DC original atualmente é composto por 22 elementos e todos os campos podem ser mapeados para campos dos padrões de metadados para objetos de aprendizagem LOM e OBAA ${ }^{12}$. É possível estender o DC com o intuito de adequá-lo às necessidades da instituição. Dessa forma, o conjunto de metadados presentes no LiSa é uma ampliação do DC, considerando alguns campos de metadados presentes no LOM e OBAA. Sendo assim, o novo conjunto obtido mantém conformidade com os padrões DC, LOM e OBAA, possibilitando a interoperabilidade do LiSa com outros repositórios e sistemas que utilizam alguns desses padrões. O conjunto de metadados do LiSa estão apresentados na Tabela 2.

\begin{tabular}{|c|l|}
\hline Campo & \multicolumn{1}{c|}{ Descrição } \\
\hline Autores & $\begin{array}{l}\text { Este campo deve informar o nome do } \\
\text { responsável intelectual pelo conteúdo. }\end{array}$ \\
\hline Título & $\begin{array}{l}\text { Este campo deve informar o título do } \\
\text { item, conforme a informação presente no } \\
\text { material. }\end{array}$ \\
\hline \multirow{2}{*}{$\begin{array}{c}\text { Data } \\
\text { de }\end{array}$} & $\begin{array}{l}\text { Esta opção apenas será exibida quando for } \\
\text { indicado que o material já foi publicado } \\
\text { ou distribuído anteriormente. Assim, } \\
\text { deve-se informar a data da primeira } \\
\text { publicação do material ( por exemplo, a } \\
\text { data de publicação de um livro ou de um } \\
\text { artigo em um periódico). }\end{array}$ \\
\hline Publicação & $\begin{array}{l}\text { Esta opção apenas será exibida quando for } \\
\text { indicado que o material já foi publicado } \\
\text { ou distribuído anteriormente. Assim, } \\
\text { deve-se informar o nome da publicação } \\
\text { do item ( por exemplo, o nome da editora } \\
\text { se for um livro ou o nome do jornal ou } \\
\text { revista caso seja um artigo). }\end{array}$ \\
\hline Citação & $\begin{array}{l}\text { Esta opção apenas será exibida quando for } \\
\text { indicado que o material já foi publicado } \\
\text { ou distribuído anteriormente. Assim, }\end{array}$ \\
\hline
\end{tabular}

\footnotetext{
${ }^{12}$ http://www.portalobaa.org/padrao-obaa
}

\begin{tabular}{|c|c|}
\hline & $\begin{array}{l}\text { deve-se inserir a referência completa do } \\
\text { material, conforme as normas ABNT } \\
\text { vigentes para citação e referência. }\end{array}$ \\
\hline Tipo & $\begin{array}{l}\text { É apresentada uma caixa de seleção } \\
\text { contendo as opções relativas ao tipo do } \\
\text { item. Caso o registro possua mais de um } \\
\text { item e estes sejam de formatos diferentes, } \\
\text { é possível selecionar dois ou mais tipos de } \\
\text { todos. }\end{array}$ \\
\hline Idioma & $\begin{array}{l}\text { É apresentada uma caixa de seleção } \\
\text { contendo as opções relativas ao idioma do } \\
\text { texto integral ou principal do material. }\end{array}$ \\
\hline $\begin{array}{c}\text { Palavras- } \\
\text { chave }\end{array}$ & $\begin{array}{l}\text { São apresentadas caixas de texto na qual } \\
\text { se deve indicar entre duas e seis palavras } \\
\text { que traduzam o conteúdo do documento. }\end{array}$ \\
\hline Abstract & $\begin{array}{l}\text { É apresentada uma caixa de texto na qual } \\
\text { se deve inserir um resumo, de preferência } \\
\text { entre três e seis linhas, relativo ao } \\
\text { conteúdo do material, indicando seus } \\
\text { pontos principais, de maneira que a partir } \\
\text { de sua leitura seja possível identificar se o } \\
\text { material é relevante ao usuário. }\end{array}$ \\
\hline Apoio & $\begin{array}{l}\text { Neste campo deve-se informar os nomes } \\
\text { dos órgãos que apoiaram a produção do } \\
\text { item, caso isso seja de seu conhecimento } \\
\text { ou esteja explícito no material. }\end{array}$ \\
\hline Descrição & $\begin{array}{l}\text { Este campo serve para informar algum } \\
\text { comentário que se deseje fazer com } \\
\text { relação ao item. Poderá ser utilizado em } \\
\text { diversos casos para apresentar } \\
\text { comentários gerais sobre o item, como } \\
\text { indicação de versão, de relação parte/todo, } \\
\text { da existência de versão acessível. }\end{array}$ \\
\hline Curso & $\begin{array}{l}\text { Este campo visa a localização do material } \\
\text { dentro do contexto da educação a } \\
\text { distância, assim deve ser preenchido com } \\
\text { o nome por extenso do curso ao qual o } \\
\text { material é vinculado. }\end{array}$ \\
\hline Disciplina & $\begin{array}{l}\text { Este campo visa a localização do material } \\
\text { dentro do escopo de um curso específico, } \\
\text { assim deve ser preenchido com o nome } \\
\text { por extenso da disciplina ao qual o } \\
\text { material é vinculado. }\end{array}$ \\
\hline Duração & $\begin{array}{l}\text { Este campo informa ao usuário a duração } \\
\text { do material quando trata-se de uma } \\
\text { animação, vídeo, videoaula, podcast ou } \\
\text { gravação de webconferência. }\end{array}$ \\
\hline $\begin{array}{l}\text { Observações } \\
\text { sobre a } \\
\text { instalação } \\
\text { e/ou acesso }\end{array}$ & $\begin{array}{l}\text { Este campo irá informar ao usuário as } \\
\text { ações necessárias para abrir o arquivo em } \\
\text { seu computador. }\end{array}$ \\
\hline
\end{tabular}

Tabela 2 - Campos do DC utilizados no LiSa. (Autoria própria) 
A escolha dos campos no LiSa foi feita com o objetivo de favorecer a busca, além de permitir aos usuários conhecer o máximo possível do conteúdo do recurso ao encontrá-lo e decidir se aquele dado material é útil ao seu processo de aprendizado sem que seja necessário consultá-lo por completo inicialmente. Ainda, após o processo de depósito o próprio DSpace gera mais alguns metadados relativos à localização do item. São eles: URI (Uniform Resource Identifier), data de depósito e coleção em que o registro aparece. A Figura 2 apresenta um exemplo de registro no LiSa.

No momento da descrição destes conteúdos no repositório, existe a preocupação em explicitar a existência de versões acessíveis do material. $\mathrm{Na}$ descrição dos materiais acessíveis, procura-se tomar cuidado em deixar claro que trata-se de uma versão acessível derivada de um material original. De acordo com as necessidades, é possível inserir novos metadados ou excluir algum que não seja mais utilizado. Dessa maneira, atualmente a equipe responsável pela gestão do LiSa está estudando a possibilidade de inserção de campos de metadados que indiquem se o material descrito no registro recebeu algum tipo de adaptação para acessibilidade ou se possui alguma versão que tenha sido adaptada. Inicialmente, pretende-se adicionar três campos, um que permita indicar se o material possui alguma adaptação voltada para acessibilidade, um segundo campo que indicará qual tratamento o material recebeu, e um terceiro campo que indicará a relação do material com outros materiais do acervo, especialmente no que diz respeito à indicação das versões do material. Na descrição de todos os campos de metadados, busca-se seguir um vocabulário único que padroniza os registros.

\section{A Página inicial Navegar - Ajuda Vocabulánio}

\section{Lîs}

\section{Livre Saber - Repositorio Digital de Materiais Didaticos - SEaD-UFSCar / Aplicativos, jogos e softwares / Música / Musikinésia / Documentos}

Use este identificador para citar ou linkar para este item. http://hdl. handle. net/123456789/22e9

\begin{tabular}{|c|c|}
\hline Titulo: & Game Design Document (GDD) \\
\hline Tipo: & Texto \\
\hline Autor(es): & $\begin{array}{l}\text { Bordini, Rogério Augusto } \\
\text { Nunes, Antônio Pedro Avanzi } \\
\text { Santiago, Daniel } \\
\text { Fonseca, Lucas Ferreira } \\
\text { Freitas, Pablo Augusto Gonçalves de }\end{array}$ \\
\hline $\begin{array}{l}\text { Data do } \\
\text { documento: }\end{array}$ & 11-Mar-2015 \\
\hline Resumo: & GDD do jogo Musikinésia. O documento descreve a mecânica, narrativa, desenvolvimento e composição do jogo. \\
\hline Descrição: & $\begin{array}{l}\text { Documento componente do jogo "Musikinésia (http://www.loa.sead. ufscar.br/musikinesia.php)" desenvolvido pela equipe do Laboratório de Objetos de Aprendizagem } \\
\text { da Universidade Federal de São Carlos (LOAJUFSCar). }\end{array}$ \\
\hline URI: & http.//hdl. handle.net/123456789/2209 \\
\hline $\begin{array}{l}\text { Aparece nas } \\
\text { coleções: }\end{array}$ & Documentos \\
\hline
\end{tabular}

Figura 2 - Registro de um material depositado no LiSa. 


\subsection{Fluxo de depósito}

O processo de depósito compreende oito etapas iniciais de descrição, seguidas de mais quatro etapas de verificação que ocorrem após a finalização do preenchimento dos dados do registro.

O primeiro passo é escolher a comunidade-topo em que o item será registrado, após essa escolha deve-se escolher a sub-comunidade e a coleção em que o material se enquadra. Então, o sistema mostrará uma tela para a descrição do registro, apresentando as seguintes opções: (i) "O registro tem mais do que um título, ex. um título em outra língua"; (ii) "O registro já foi publicado ou distribuído publicamente"; (iii) "O registro é composto por mais do que um arquivo" ou ainda é possível seguir com o processo sem escolher nenhuma das opções. Feito isso, começam as etapas de descrição do material.

Na primeira etapa a descrição é voltada ao preenchimento dos metadados de "autor", "título", "idioma" e "tipo". Caso as opções (i) ou (ii) tenham sido escolhidas, também serão mostrados os campos: "data de submissão", "publicação" e "citação". Encerrado o preenchimento destes campos, segue-se para segunda tela de descrição que traz os campos com os metadados: "palavras-chave", "resumo", "apoio", “descrição", "curso", "disciplina", "duração" e "observações de instalação e uso". A tela seguinte é destinada ao carregamento do arquivo (ou dos arquivos, caso a opção (iii) tenha sido marcada). Além do carregamento do arquivo, é possível preencher um campo com o texto de descrição relativo ao arquivo especificamente (Por exemplo: Parte 1) . Finalizado, o sistema segue para uma página que mostra o registro completo já realizado para conferência e permite que possíveis correções sejam feitas. A etapa seguinte é a concessão da licença "CreativeCommons", seguida da confirmação da finalização do depósito.

De acordo com as configurações escolhidas no momento de criação das comunidades, subcomunidades e coleções, após a finalização do depósito o registro é enviado para a página de trabalho do administrador, para realização da conferência do registro. Esta verificação é composta de quatro etapas: "verificação dos metadados"; "verificação e edição dos metadados"; "verificação final do registro" e "aceite final do depósito".

Somente após a conferência e liberação é que o registro passa a ficar disponível para o acesso público. Uma vez disponível, o registro pode ser retirado, caso haja necessidade. Na Figura 3 é possível visualizar o processo completo de depósito do LiSa.

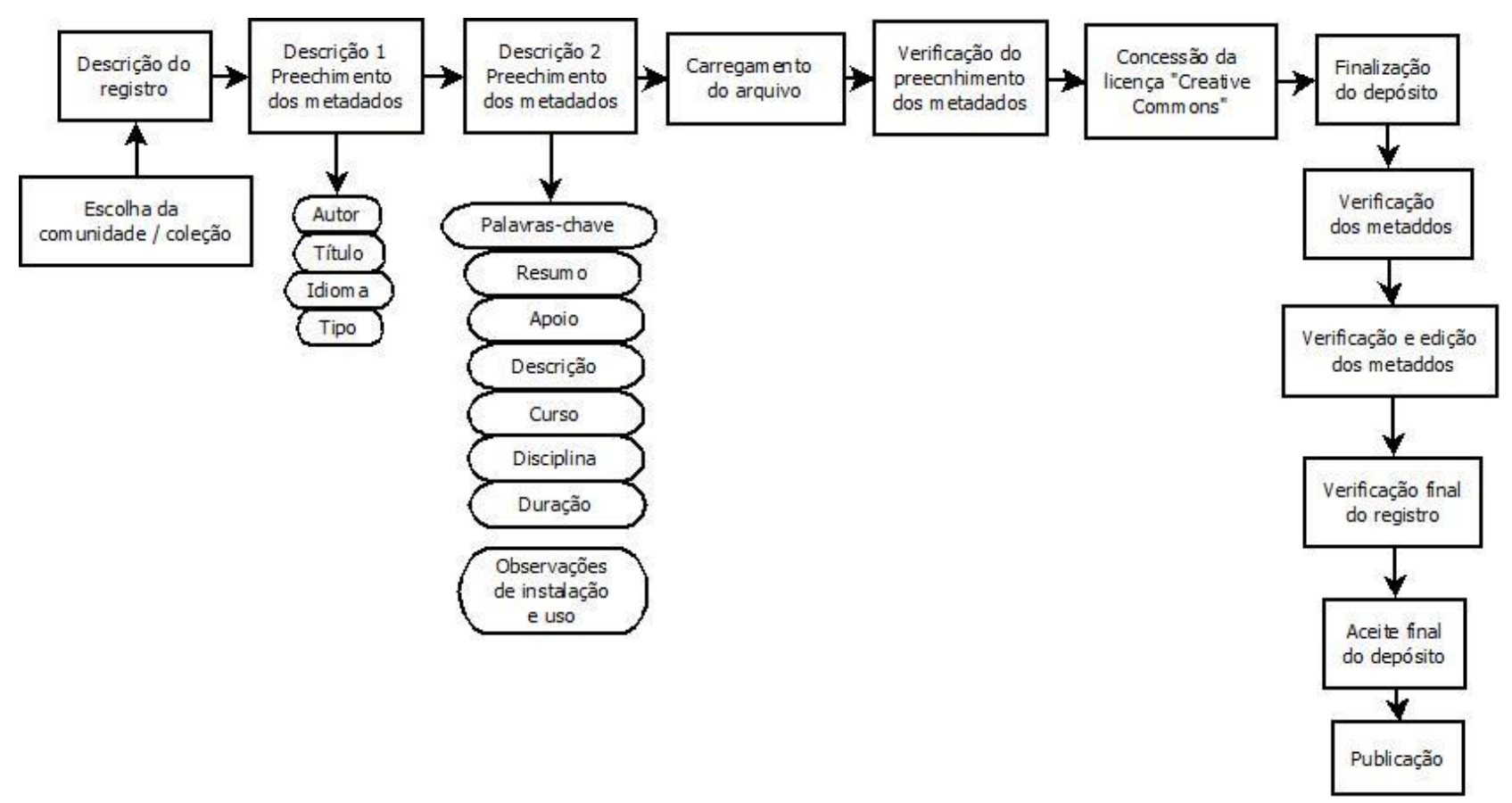

Figura 3- Fluxograma de submissão de materiais ao repositório. (Autoria própria). 


\section{Resultados iniciais}

Até novembro de 2014, o LiSa possuía 1361 registros, divididos em 6 comunidades-topo, 11 comunidades, 9 subcomunidades e mais de 50 coleções. São 1800 termos descritores de assuntos para registros de 221 autores. Dos 1361 registros, 51 possuem versões adaptadas para acessibilidade. A Tabela 3 apresenta a quantidade de registros feitos por ano desde 2011, quando o LiSa foi implantado:

\begin{tabular}{|l|l|}
\hline Ano & Registros \\
\hline 2011 & 418 \\
\hline 2012 & 165 \\
\hline 2013 & 400 \\
\hline 2014 & 378 \\
\hline
\end{tabular}

Tabela 3 - Registros por ano realizados no LiSa

Conforme já citado, o $\mathrm{LiSa}$ recebe materiais em diferentes formatos. Assim, na Figura 4 é possível observar a distribuição da quantidade dos materiais publicados de acordo com seus tipos.

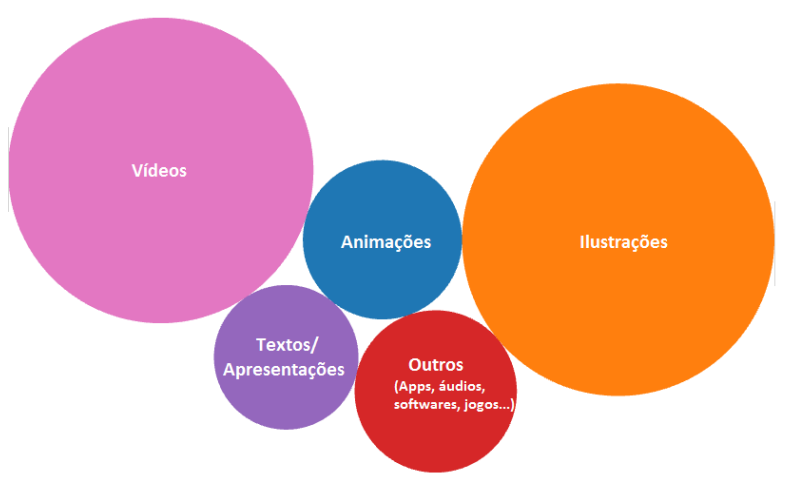

Figura 4- Materiais por tipo. (Autoria própria)

A primeira diferença entre o LiSa e muitos outros repositórios nota-se da observação do infográfico: vídeos e ilustrações representam mais da metade do conteúdo do repositório. No LiSa estes materiais se destacam pois são, também, materiais comumente utilizados como recursos de aprendizagem na educação a distância.

Entre julho de 2012 e julho de 2014, a SEaD realizou um projeto de avaliação dos materiais didáticos utilizados nos cursos de graduação a distância que a secretaria apoia. Além da avaliação pedagógica, também era solicitado aos avaliadores que indicassem se os materiais poderiam ser depositados no LiSa ou se deviam seguir para algum revisão ou reelaboração. Foram avaliados 2000 materiais. A Figura 5 mostra a relação entre a quantidade de materiais avaliados, indicados para a publicação e efetivamente publicados no LiSa.

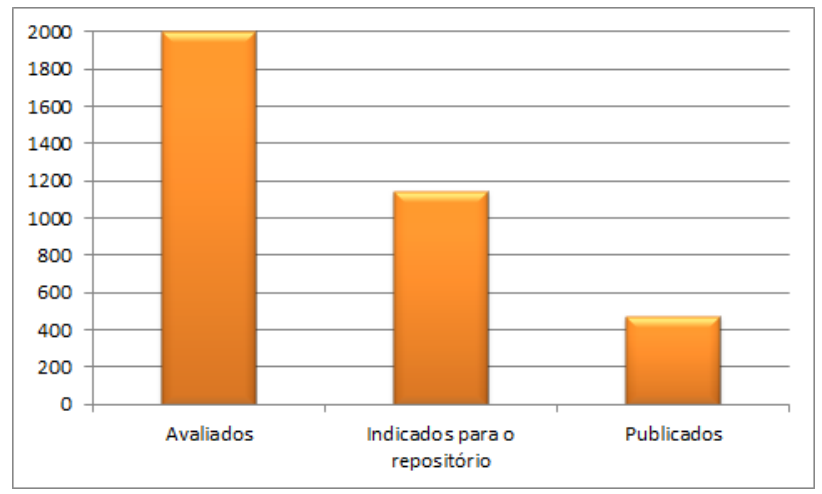

Figura 5- Relação Avaliação X Publicação de materiais no LiSa. (Autoria própria)

A avaliação foi desenvolvida no escopo de um projeto da $\mathrm{SEaD}$ focado na análise pedagógica dos materiais didáticos utilizados nos cursos de graduação a distância apoiados pela SEaD. Esse trabalho foi desenvolvido em conjunto com a equipe do repositório, com o intuito de obter uma avaliação externa dos materiais produzidos, antes de sua publicação no LiSa. No período de dois anos foram avaliados 2000 materiais, dos quais 1144 foram indicados para a submissão no repositório. Pela Figura 5, é possível observar que os materiais que chegaram à publicação não somam nem a metade dos indicados, tendo em vista que apenas 476 materiais foram publicados. À primeira vista parece um número baixo, pois a relação entre avaliados e publicados é baixa. No entanto, a meta da avaliação não era avaliar apenas materiais candidatos a serem publicados no LiSa, mas todos os recursos de cada disciplina. Dessa maneira, com relação aos materiais avaliados e indicados para o repositório, mas não publicados devem-se considerar diversos fatores que levaram a não publicação. Entre estes fatores estão: ausência de confirmação da autoria no material; negativa na autorização por parte do autor; limitações quanto a formatos ou suportes; restrições relacionados a direitos autorais ou norma de publicação e não adequação de alguns tipos de materiais ao escopo do repositório.

Os novos recursos que estão sendo produzidos pelas equipes da $\mathrm{SEaD}$ em conjunto com docentes estão sendo encaminhados para publicação logo após a finalização da produção. A qualidade desses materiais é assegurada por serem de autoria dos docentes responsáveis pelas disciplinas terem o seu planejamento e produção totalmente acompanhada pelas equipes de planejamento e produção de materiais didáticos da SEaD-UFSCar.

Como pôde ser observado nos dados apresentados, o Livre Saber já possui um conjunto abrangente e diversificado de recursos educacionais, em diferentes áreas de conhecimento e em diferentes formatos. A 
publicação desses materiais tem sido importante para a preservação,compartilhamento e reuso do rico acervo de recursos educacionais que vem sendo criado no escopo dos cursos oferecidos na modalidade EaD na UFSCar.

Os próximos passos da equipe serão: (i) a reorganização de algumas Comunidades, Subcomunidades e Coleções; (ii) a migração do DSpace para a versão 4.2; (iii) uma avaliação e redesign da interface do LiSa; (iv) a extensão do conjunto de metadados para comportar a catalogação de dados específicos para recursos acessíveis para pessoas com algum tipo de deficiência. Além disso, pretende-se trabalhar na divulgação do repositório, bem como na sensibilização de docentes sobre a importância do licenciamento de suas produções sob licenças que protejam a autoria, mas que permitam um reuso pleno desses recursos, contribuindo para uma educação aberta e sustentável.

\section{Considerações Finais}

Um dos grandes desafios em nosso país é a democratização da educação em todos os níveis de formação e a construção de cenários mais favoráveis para o desenvolvimento de processos de ensino-aprendizagem de melhor qualidade. Nesse contexto, é imprescindível que todos trabalhem de forma mais integrada, construindo colaborativamente novos saberes e soluções. A produção e compartilhamento de Recursos Educacionais Abertos pode contribuir de forma significativa nessa direção, possibilitando uma educação mais democrática e sustentável.

Vale destacar que o desenvolvimento de REA não tem muito valor se estes não puderem ser encontrados facilmente. Dessa forma, a organização dos REA em repositórios digitais, com uma catalogação adequada por meio de um conjunto de metadados significativo e em conformidade com os principais padrões, é importante para otimizar a busca e a recuperação, além de possibilitar a interoperabilidade com outros repositórios e sistemas. Iniciativas de federações de repositórios educacionais como a Federação Educa Brasil também podem contribuir para o a recuperação e acesso mais efetivo desses recursos. Além disso, a divulgação e sensibilização de professores e alunos para o uso e também para a produção de REA é premente.

Este artigo apresentou o repositório digital Livre Saber, implantado na UFSCar para a organização, preservação e compartilhamento dos recursos educacionais abertos que vêm sendo produzidos no escopo dos cursos oferecidos nesta Universidade na modalidade EaD. Espera-se que este trabalho possa incentivar e contribuir com outras iniciativas de implantação de repositórios digitais de recursos educacionais abertos.

\section{Referências}

[1] PINTO,S. M; RIBEIRO, S. F.; SERRA, A. R. C. REA na Universidade Aberta do Brasil: limites e perspectivas. In: Recursos Educacionais Abertos \& Redes Sociais, páginas 343-354. São Luis: EdUEMA, 2013. Disponível em: <http://oer.kmi.open.ac.uk/?page_id=3766>. Último acesso em nov. 2014.

[2] D'ANTONI, S.; SAVAGE, C. (Org.). Open Educational Resources - Conversations in Cyberspace. Paris: UNESCO, 2009. Disponível em:<http://www.col.org/SiteCollectionDocumen ts/country-information/OER_Full_Book.pdf $>$. Último acesso em nov. 2014.

[3] BUTCHER, N. A Basic Guide to Open Educational Resources (OER). Asha Kanwar (COL) and Stamenka Uvalic'-Trumbic' (UNESCO), 2011. ISBN 978-1-894975-41-4. Disponível em:

<http://www.col.org/PublicationDocuments/Basi c-Guide-To-OER.pdf>. Último acesso em nov. 2014.

[4] WILEY, D. Impediments to Learning Object Reuse and Openness as a Potential Solution. Revista Brasileira de Informática na Educação, Volume 17, Número 3, páginas 8-10, 2009. Disponível em: <http://www.br-ie.org/ pub/index.php/rbie/article/view/1022/1016 >. Último acesso em nov. 2014.

[5] OPEN SOCIETY FUNDATIONS \& SHUTTLEWORTH FOUNDATION. Cape Town Open Education Declaration: Unlocking the promise of open educational resources. Cape Town, Africa, 2007. Disponível em: <http://www.capetowndeclaration.org/read-thedeclaration>. Último acesso em nov. 2014.

[6] HAYES, H. Digital Repositories: Helping universities and colleges. JISC Briefing Paper, 2005. Disponível em:

$<$ http://www.jisc.ac.uk/uploaded_documents/HE _repositories_briefing_paper_2005.pdf > . Último acesso em nov.2014.

[7] WALTERS, Tyler O.. Reinventing the Library: How Repositories Are Causing Librarians to Rethink Their Professional Roles. Libraries And The Academy, Baltimore, v. 7, n. 2, p.213225, 2007. Disponível em:

$<$ http://muse.jhu.edu/journals/portal_libraries_an 
d_the_academy $/ \mathrm{v} 007 / 7.2$ walters.pdf $>$. Acesso em: nov. 2014

[8] HEERY, R.; ANDERSON, S. Digital

Repositories Review. Bristol: JISC, 2005.

Disponível em:

<http://www.jisc.ac.uk/uploaded_documents/dig ital-repositories-review-2005.pdf>. Último acesso em: nov. 2014.

[9] NAJJAR J., DUVAL E., TERNIER S., and NEVEN F., Towards Interoperable Learning Object Repositories: The Ariadne Experience. In: Proceeding of IADIS International Conference WWW/Internet, 2003, Vol. I, P. 219226 ISBN 972-98947-1-X. Último acesso em: nov. 2014.

[10] MASAR, I. DSpace 4.x Documentation - OAI 2.0 Server . Disponível em: <https://wiki.duraspace.org/display/DSDOC4x/ OAI+2.0+Server>. Último acesso em: nov. 2014.

[11] ASSOCIAÇÃO BRASILEIRA DE NORMAS TÉCNICAS. NBR 6023 Informação e documentação - Referências - Elaboração. Disponível em:

<www.habitus.ifcs.ufrj.br/pdf/abntnbr6023.pdf> Último acesso em: nov. 2014. 